\title{
Desenvolvimento de dois serviços de comunicação, síncrona e assíncrona, num processo de participatory design, para o cidadão idoso
}

\author{
Sónia de Almeida Ferreira', Ana Isabel Veloso², Óscar Mealha³ \\ Recebido em: 06/05/2013. Aprovado em: 31/05/2013. Disponibilizado em: 24/06/2013
}

\begin{abstract}
1. Sónia de Almeida Ferreira é Doutoranda em Informação e Comunicação em Plataformas Digitais e mestre em Comunicação Multimédia pela Universidade de Aveiro. É investigadora no projeto SEDUCE - PTDC/CCI-COM/111711/2009 e bolseira de investigação SFRH/ BD/ 70092/ 2010- COMPETE, FEDER, FCT de Lisboa, Portugal. É Assistente Convidada na Escola Superior de Educação, Instituto Politécnico de Viseu, desde setembro de 2010. e-mail: soniaaferreira@ua.pt.

2. Ana Isabel Veloso é Doutora em Ciências e Tecnologias da Comunicação da Universidade de Aveiro; é mestre em Engenharia Biomédica e licenciada em Engenharia Informática pela Universidade de Coimbra. Atualmente é docente no Departamento de Comunicação e Arte da Universidade de Aveiro e membro da direção do centro de pesquisa do CETAC.MEDIA. Coordenadora de vários projetos de pesquisa - SEDUCE; EYE ON GAMES; EYE ON TV; Interactive Magic Places, People and Practices. A sua área de pesquisa são na comunicação mediada tecnologicamente, nas narrativas e jogos interativos, na interação humanocomputador. É autora de inúmeras publicações nacionais e internacionais. Orienta anualmente diversos alunos de Mestrado e de Doutoramento. Organizou a Conferência Videojogos2009. e-mail: aiv@ua.pt.

3. Óscar Mealha é Doutor em Engenharia Electrotécnica pela Universidade de Aveiro, em 1995, tem cerca de 20 anos de investigação na área de Interacção Humano-Computador, usabilidade e visualização de informação, e destes, cerca de 16 anos a trabalhar para a área das Ciências e Tecnologias da Informação e Comunicação. É professor associado com agregação no Departamento de Comunicação e Arte da Universidade de Aveiro e membro do CETAC.MEDIA. e-mail: oem@ua.pt.
\end{abstract}

\section{Resumo}

Numa sociedade em permanente avanço tecnológico, acompanhado por um rápido processo de envelhecimento demográfico, torna-se necessária a diminuição do isolamento social decorrente das perdas físicas e psicossociais e o dissipar de preconceitos sofridos por este grupo social. Este artigo propõe um referencial teórico sobre a usabilidade das interfaces digitais utilizadas pelo cidadão idoso, enunciando as orientações de usabilidade para construção de Websites usáveis por este grupo etário. Além disso, reporta o resultado da investigação empírica, onde se estudaram os resultados da participação dos seniores no desenvolvimento de dois serviços de comunicação, síncrona (instant messanging) e assíncrona (correio eletrónico). Como consequência desta abordagem apresentam-se duas propostas para a interface gráfica dos referidos serviços.

Palavras-chave: Comunicação Mediada por Computador; Inclusão digital; Serviços de Comunicação Síncrona e Assíncrona; Cidadão Idoso; Participatory Design 



\section{Introdução}

O processo de interação entre sistemas tecnológicos e o ser humano, nomeadamente o cidadão idoso, por envolver participantes de natureza distinta, requer um estudo transdisciplinar (Freitas, 1994) que elabore a instrumentalização necessária e adaptada ao desenvolvimento das interfaces dos sistemas computacionais.

Neste entendimento, cabe às Ciências da Computação nomeadamente a disciplina da Interação Humano-Computador (IHC) fornecer aos investigadores e designers explicações e previsões para os fenómenos de interação e resultados práticos para o design da interface (Lindgaard, 1994). O contexto de utilização exerce também uma influência determinante na usabilidade e, como tal, deve ser considerado por investigadores e designers. Mais do que desenvolver um sistema, o desafio da usabilidade requer o desenvolvimento da sua aplicação integrada no contexto de uso do utilizador.

$\mathrm{Na}$ nossa cultura, o computador surgiu como uma ferramenta exclusiva para especialista: físicos, programadores e engenheiros de sistemas computacionais. Como consequência, os primeiros trinta anos da história do computador foram marcados pelo design centrado na tecnologia, situação que previa a adaptação do utilizador à máquina. Esse cenário mudou radicalmente nas últimas décadas, momento em que os computadores passaram a ser incorporados na grande maioria das profissões e apropriados por um largo espectro de utilizadores.

Não devemos esquecer que na atualidade existem três tipos diferentes de analfabetismo a serem erradicados, o da lecto-escritura, o sociocultural e o tecnológico (Barbosa, Cheiran \& Vieira,
2008). Em Portugal já se vislumbre uma tendência positiva na escolarização patente nas gerações mais novas. De acordo com o gabinete de estatísticas europeias, no escalão etário dos 50 a 64 anos, apenas 12 em cada 100 tinham o secundário, no escalão dos 40 a 49 anos, esta percentagem era de 19 por cento e nas idades compreendidas entre os 30 e os 39 anos era de 24 por cento (Casanova, 2001). Justifica-se assim o surgimento de programas e estudos voltados para a inclusão digital de maneira a reduzir as barreiras que se interpõem entre $o$ cidadão e a informação, e ainda, entre o acesso à informação e o conhecimento, particularmente dos seniores (Comissão Europeia, 2006). Por esse motivo, são necessárias interfaces mais eficazes que possam atender a uma variedade cada vez maior de utilizadores, devendo optar-se por métodos e técnicas na construção de websites que permitem que a mensagem seja devidamente interpretada.

Este artigo atende a essa preocupação e objetiva oferecer algum conhecimento teórico para que o design de interfaces de utilizador se aproxime do seu propósito de design para usabilidade, em contexto de uso pelo

cidadão idoso. Na primeira parte deste referencial faz-se um enquadramento ao tema, apresentando-se as implicações do processo de envelhecimento na interação com o computador, enunciam-se as diretrizes de usabilidade que devem ser tidas em conta quando se projeta um ambiente digital para o cidadão idoso e estuda-se o envolvimento do sénior no processo de design, estudando as vantagens $\mathrm{e}$ as desvantagens associadas.

A componente empírica deste estudo apresenta o contributo dos seniores no desenvolvimento de dois protótipos de baixa fidelidade de serviços de comunicação síncrona e assíncrona, instant messaging $\mathrm{e}$ 
correio eletrónico.

\section{Enquadramento}

\subsection{Envelhecimento e a Interação Idoso- Computador}

A tabela 1 apresenta a relação entre as alterações do processo de envelhecimento e as dificuldades que surgem na interação do utilizador idoso com o computador e alguns aspetos que corrigidos podem ajudar a comunicar.

\begin{abstract}
Alterações do processo de envelhecimento
Visuais: dificuldades para discriminar detalhes de objetos próximos; dificuldades para leitura, para a visão à noite e na interpretar a visão nas mudanças rápidas de ambientes com luminosidade diferente; diminuição da sensação luminosa e cromática; 'vista cansada', em que diminui-se a qualidade da visão de perto; cataratas; processos degenerativos fisiológicos na retina (Kachar, 2003 cit. por Vechiato e Vidiotti, 2008).
\end{abstract}

Auditivas: diminuição gradual da capacidade auditiva; zumbido; dificuldade quanto à atenção em casos de ruído ambiental ou conversas em grupo; baixa tolerância a sons de alto volume e grande intensidade (Kachar, 2003, cit. por Vechiato e Vidiotti, 2008).
Interação Idoso - Computador

A diminuição da capacidade de visão pode afetar a Interação Humano - Computador (IHC) quando: o tamanho das fontes disponíveis nos softwares e/ou ambientes informacionais digitais são muito pequenos; não há contraste significativo de cores entre texto e fundo; não há iluminação suficiente para leitura; o hardware não tem tecnologia suficiente para suportar as tecnologias que o software oferece.

A diminuição da capacidade de audição pode interferir na IHC quando: os sons disponibilizados pelos softwares e/ou ambientes informacionais digitais não se apresentam de maneira clara; não há facilidade ou disponibilização do recurso de aumentar/reduzir o volume do som; os sons de videoconferências, por exemplo, apresentam falhas; não há possibilidade de ouvir som devido ao barulho do ambiente de acesso.

Afetam a IHC na utilização dos aspetos físicos de interação (ergonomia do hardware). 2002, cit. por Vechiato e Vidiotti, 2008).

Atenção: dificuldades quanto à atenção dividida, ou seja, diminuição da capacidade de dar atenção a várias coisas ao mesmo tempo (Sales, 2002, cit. por Vechiato e Vidiotti, 2008).

Perceção: diminuição na capacidade de descobrir figuras ou formas inseridas em padrões complexos e há declínios na habilidade para reconhecer objetos fragmentados ou incompletos (Sales, 2002, cit. por Vechiato e Vidiotti, 2008).

Memória: alterações mais salientes relacionadas com a memória secundária, ou seja, à memória de curto prazo (Kachar, 2003, cit. por Vechiato e Vidiotti, 2008).

Aprendizado: relacionadas com as alterações de atenção, perceção e memória (Preece; Rogers; Sharp, 2002)
Interferem na IHC quando os seniores precisam ativar a atenção seletiva por entre muitas opções, assim como quando são exibidos diversos elementos e os utilizadores não conseguem prestar atenção em todos os elementos, por exemplo, diversas promoções com texto e imagem num ambiente de comércio eletrónico.

Afetam a IHC quando os seniores não reconhecem/ percebem elementos misturados e/ou fragmentados, como por exemplo, textos, imagens e sons.

Prejudicam a IHC quando os seniores não conseguem memorizar os recursos que acabaram de aceder.

Interferem na IHC quando os utilizadores seniores não conseguem usar os processos cognitivos de atenção, perceção e memória adequadamente, prejudicando a aprendizagem. 


\begin{tabular}{l|l}
\hline $\begin{array}{l}\text { Linguagem: relacionadas com a produção e receção da } \\
\text { linguagem, no que diz respeito à leitura, fala e audição } \\
\text { (Preece, Rogers, Sharp, 2002). }\end{array}$ & $\begin{array}{l}\text { Prejudicam a IHC quando os seniores não conseguem } \\
\text { utilizar os sistemas sensoriais relacionados com a visão e } \\
\text { a audição para processamento da linguagem. }\end{array}$ \\
\hline $\begin{array}{l}\text { Resolução de problemas, planeamento, raciocínio e e } \\
\text { tomada de decisões: relacionadas mas com o }\end{array}$ & $\begin{array}{l}\text { Interferem na IHC quando os seniores não conseguem } \\
\text { gerir erros no uso de um software e/ou ambiente } \\
\text { indivíduo em si só, do que com os seniores em geral } \\
\text { informacional digital, utilizar opções de procura } \\
\text { (Preece, Rogers, Sharp, 2002) }\end{array}$ \\
$\begin{array}{l}\text { avançada, encontrar determinada informação por } \\
\text { motivos de sobrecarregamento de elementos gráficos } \\
\text { e/ou textuais. }\end{array}$ \\
\hline
\end{tabular}

Tabela 1 - Relação das alterações do processo de envelhecimento e dificuldades na Interação IdosoComputador

Desta forma, é urgente compreender as limitações deste grupo e identificar as atividades desempenháveis e satisfatórias a fim de estimular meios de reinserção desses indivíduos nas relações sociais contemporâneas (VERONA et al., 2006).

\subsection{Usabilidade e o utilizador idoso}

No nosso quotidiano estamos rodeados por sistemas e dispositivos computacionais interativos com os quais lidamos frequentemente, muitas vezes de forma inevitável: computador, telemóvel, caixa de multibanco, automóvel. Procuramos nesses artefactos o suporte para a nossa atividade enquanto humanos, possibilitando tornar as tarefas mais fáceis, rápidas, simples, e até mais agradáveis e seguras.

Em 1981, Moran define, formalmente, a interface de um sistema como a componente de um sistema informático com o qual a pessoa entra em contacto, seja de forma física, percetiva ou conceitualmente (Moran, 1981). Em meados da década de 80 é cunhado o termo IHC para definir uma nova área de estudo, fruto da vulgarização do conceito de "computador pessoal" e apropriação por utilizadores não especializados (Barbosa, Cheiran \& Vieira,
2008). O foco deixa de estar centrado apenas na interface de um sistema e passa a abranger todos os aspetos relacionados com a interação entre o utilizador e o sistema (Preece, et al., 1994).

Desta forma, a IHC caracteriza-se por ser transdisciplinar e encontra-se especificamente na interceção das ciências da computação, ciência da informação, ciências da comunicação e utiliza ainda outros conhecimentos, métodos e técnicas das ciências sociais e humanas.

De acordo com Nielsen (2003), a usabilidade é o atributo de qualidade que avalia a facilidade de utilização de uma interface. Além disso, refere-se aos métodos de aperfeiçoamento da utilização do ambiente virtual durante a sua criação. Segundo o autor, a usabilidade assenta num conjunto de cinco elementos de qualidade: a facilidade de aprendizagem - o sistema deve ser fácil de assimilar para que o utilizador o possa utilizar facilmente; eficiência - a máxima eficiência do sistema equivale a uma maior produtividade conseguida pelo utilizador; facilidade de memorização - o sistema deve ser de fácil memorização, para que quando o utilizador retoma o sistema, depois de algum tempo sem o utilizar, se lembre facilmente de o usar; segurança - o 
sistema deve antever os erros e evitar que os utilizadores os cometam e, quando ocorrem, deve recuperar o que foi perdido; e satisfação - se o sistema corresponder a uma experiência de uso agradável, os utilizadores sentem-se satisfeitos com a situação de interação ocorrida.

A usabilidade prende-se com a simbiose de interação entre os utilizadores e os sistemas tecnológicos (Sousa, 2009). Assim, quando projetamos a construção de um sistema ele deve estar associado às características dos utilizadores, das atividades e tarefas a serem desempenhadas, dos equipamentos e ambientes físicos (Sales \& Cybis, 2002; Raabe, et al., 2005). Em contexto europeu e para regular o que deve ser um estudo de usabilidade, foi instituída a norma ISO 9241 (ISO, 1998), especificamente a sua parte 11 para responder às necessidades de enquadramento da "avaliação de usabilidade".

No que diz respeito aos utilizadores seniores, os ambientes informacionais digitais devem ser desenvolvidos refletindose as particularidades existentes neste publico-alvo específico, assim como a quantidade de recursos que os mesmos podem usar na Internet (Vechiato \& Vidotti, 2008). Nesse sentido, a ergonomia da informação disponível nos ambientes digitais deve potenciar a criação de interfaces que permitam a inclusão digital desse grupo específico, por meio de elementos que possibilitem o acesso equitativo aos conteúdos disponíveis digitalmente (idem). A avaliação de ambientes virtuais deve, então, oferecer meios para enumerar os problemas ou apresentar soluções de usabilidade de interfaces utilizadas pelo cidadão idoso.

\subsubsection{Diretrizes de Design para o Utilizar} Idoso
Têm surgido várias investigações feitas em contexto de utilização das TIC pelos seniores e que nos permitem definir guias de usabilidade para a construção de Websites usáveis pelo grupo, cita-se algumas das investigações desenvolvidas por Nielsen, em 2002, pelo National Insitute on Age, também em 2002, mais recentemente, e por Zaphiris et al., em 2005.

Depois de revistas todas as diretrizes projetadas pelos autores citados, enunciamos agora apenas as comuns nas três investigação:

- O número de etapas ou passos necessários para completar uma tarefa devem ser diminuídos. A probabilidade de cometer erros durante uma longa sequência de operações é maior quanto maior for essa mesma série e, além disso, é também superior quando os utilizadores são seniores;

- Os seniores são menos experientes na utilização das TIC pelo que podem não possuir os conhecimentos básicos fundamentais para interagir eficazmente com elas. Assim, as informações necessárias para executar corretamente qualquer tarefa devem estar imediatamente visível na interface, evitando o recurso à intuição ou à memorização de longas sequências de operações;

- Nas características de interação das hiperligações, devem existir estratégias de cor e de tipo de letra para diferenciar as hiperligações ativas e visitadas; as estratégias de design devem facilitar o reconhecimento das áreas e das tarefas a realizar, apostar sempre na consistência e clareza; nas cores optar por utilizar sempre bons contrastes entre as letras e a cor de fundo; e na procura de informação devem existir sempre que 
possível mecanismos de pesquisa interna dentro do próprio website;

- Coerência: o envelhecimento envolve uma diminuição na capacidade de memória e de trabalho. Os utilizadores seniores tendem a confiar em estímulos externos e no apoio ambiental para obter informações e respostas corretas à memorização, por isso é importante a implementação de um projeto que dê mais evidência à relação entre estímulos e respostas aprendidas;

- organização e estruturação adequadas das informações de forma a evitar a complexidade visual e reduzir o tempo de procura de informações básicas;

- Compatibilidade: as opções oferecidas na interface devem ser compatíveis com as opções do utilizador.

Por exemplo, é importante que uma tarefa rotulada de menu corresponda àquilo que os utilizadores esperam que seja, aproveitando a experiência dos utilizadores e os conhecimentos já adquiridos.

- No design das janelas devem evitar-se as barras de deslocamento horizontal e vertical e evitar manter mais do que uma janela aberta.

- Os utilizadores devem ser ajudados através da disponibilização de mensagens de erro, manuais e ajuda.

- Os seniores são particularmente propensos a cometer erros nalgumas etapas das tarefas, portanto, a aplicação deve fornecer informações sobre o tipo de erros, consequências e estratégias de recuperação;

- De particular importância é o uso de ícones, das representações simbólicas. Eles podem ser muito úteis na transmissão de informações de forma simples e direcionada. Esses ícones devem ser reconhecidos e compreendidos pelos utilizadores, sem qualquer ambiguidade ou incompreensão. Por isso, quem desenvolve as interfaces deve certificar-se de que os utilizadores seniores já aprenderam e poderiam facilmente discriminar e reconhecer as mensagens e o seu significado. As representações simbólicas podem adquirir maior relevo se considerarmos que nem todas as pessoas partilham a mesma língua mas utilizam, muitas vezes, as mesmas ferramentas de informação e comunicação. Surge assim a necessidade de ícones internacionais.

Embora pouco discutida, a audição também deve ser considerada. Ao longo do processo de envelhecimento a audição diminui, pelo que os produtos tecnológicos devem compensar essas limitações com outros tipos de informações, permitindo que os utilizadores seniores possam usufruir de uma boa compreensão da linguagem falada.

\section{Envolver os seniores no processo de design}

Desenvolver um ambiente virtual adaptado ao cidadão idoso passa por integrar esse utilizador no processo de design, considerando toda a sua experiência. Morrell et al. (2003), Hawthorn (2003) e Fisk et al. (2004) insistem nessa visão e salientam que isso deve ocorrer nem que seja apenas na fase de avaliação dos produtos.

Gregor, Newell e Zajicek (2004) utilizaram a abordagem de user-centered design com seniores e verificaram que essas práticas devem ser adaptadas quando esse público está envolvido, com a consciência de que possuem características próprias do processo de envelhecimento. Os autores propõem uma nova metodologia designada de Sensitive 
Design Inclusive, assente no pressuposto de "usabilidade universal" e tendo em consideração os aspetos demográficos, a aprendizagem e as características comportamentais do público idoso.

Battle e Hoffman (2004) são mais críticos e afirmam que os processos de usercentered design raramente são aplicados na criação de aplicações acessíveis. Argumentam que tentar projetar uma solução que satisfaça as necessidades de todos, incluindo os seniores, é suscetível de conduzir a uma solução insuficiente e pobre. Como proposta, sugerem a criação de um conteúdo que possa assumir diferentes formas a fim de servir vários tipos de utilizadores.

Chisnell, Lee e Redish (2004) nos seus estudos para a American Association of Retired Persons' fornecem alguns conselhos para a recruta e trabalho que vise a participação do público idoso. Durante as sessões de participatory design aconselham: deixar os participantes confortáveis, clarificando o objetivo e tendo paciência para que se envolvam perfeitamente; mantêlos focados, uma vez que muitos participantes seniores têm sempre imensas histórias para contar; ouvi-los atentamente quando revelam os seus medos e benefícios sobre os computadores e a Internet; evitar linguagem formal sobre informática; dar-lhes tempo, já que os seniores demoram mais $25 \%$ do tempo a desempenhar uma tarefa do que os indivíduos jovens; permitir que, quando uma tarefa se torna complicada, os utilizadores possam "pensar" em voz alta para refletirem; e, por muito tentador que seja ajudar, não conduzir totalmente os seniores nas tarefas, isso inibe o pensamento e o esforço em aprender.

Raabe (et al., 2005) apresenta uma investigação onde promove a inclusão do idoso como participante no processo de criação de uma comunidade online com vista à utilização de comandos de voz como alternativa aos periféricos tradicionais (teclado e rato). Os autores utilizam uma abordagem de participatory design, onde o utilizador idoso é incluído no grupo de trabalho com três tipos de envolvimento: informativo, consultivo e participativo. $\mathrm{Na}$ fase participativa, organizou-se uma oficina com quatro seniores e a utilização do software IBM ViaVoice Standard. Como resultado, a equipa de investigação verificou que a fase participativa não poderia ser desenvolvida, já que o utilizador não possuía conhecimentos suficientes para poder criticar e apresentar soluções. Este estudo revela-se importante para esta pesquisa na medida em que alerta para as limitações do utilizador enquanto participante ativo do desenvolvimento de uma interface.

\section{Investigação Empírica}

A operacionalização do estudo realizouse em duas Instituições Particulares de Solidariedade Social (IPSS) do concelho de Aveiro, parceiras nestes projetos de desenvolvimento social - o Patronato Nossa Senhora de Fátima de Vilar (PNSFV) e o Centro Paroquial de São Bernardo (CPSB). Os critérios de seleção da amostra foram: idade igual ou superior a 65 anos, participação voluntária e estado cognitivo considerado normal (despiste de demência através da aplicação do Mini Mental State Examination).

\subsection{Sessões de recolha de dados - observação participante}

Com o intuito de fazer a recolha de dados qualitativos relativos à interação dos seniores com as TIC foi concebido uma série de atividade que compreendiam a utilização do Microsoft Office Word (escrita e 
formatação de textos), exploração do Windows Live Hotmail, Messenger e do Google.

As sessões realizaram-se duas vezes por semana, com uma duração média de 90 minutos, durante os meses de março e abril de 2010 .

É importante referir que, independentemente do que fora elaborado previamente no plano de atividades, as sessões estiveram sempre dependentes da velocidade de aprendizagem de cada idoso. Kachar (2002, cit. Por Verona et. al, 2006), no seu estudo sobre a relação dos seniores com a aprendizagem do computador, revelou que as dificuldades que os mesmos apresentam podem ser superadas através de estratégias de aprendizagem adequadas, como respeitar o ritmo individual.

Os seniores já tinham utilizado previamente o computador, contudo foi necessário iniciar as sessões com operações básicas, como ligar e desligar o computador, tal como com as funções gerais do computador. Para a realização das atividades com utilização das ferramentas de comunicação o investigador elaborou um guião de apoio para os seniores, com conteúdos acerca de cada um dos serviços de comunicação.

\subsection{Dados da observação participante}

Os dados recolhidos durante a realização desta investigação foram registados num diário de campo, em registo audiovisual e em grelhas observações de ordem qualitativa de acordo com as atividades realizadas.

As grelhas de observação procuraram registar sobretudo as dificuldades de utilização das TIC pelos seniores de ambas as instituições, nomeadamente das ferramentas Web e dispositivos do computador.
Relativamente aos dispositivos, computador e rato, os seniores de ambas as instituições mostraram interesse em utilizar o computador portátil em vez do fixo, justificando-se com a necessidade de se sentirem tecnologicamente atualizados, contudo os seniores do CPSB, depois de receberem uma nova doação de computadores fixos, confessaram que as dimensões do dispositivo tornam-no mais funcional. Importa ainda referir que um dos seniores mostrou muitas vezes dificuldades de visualização no monitor, uma vez que se tratava de um modelo que não é antibrilho.

Nas primeiras sessões dedicadas às TIC a maioria dos seniores mostrou dificuldades em utilizar o rato e em tomar consciência do mesmo nas ações expostas no monitor, justificado pelo facto de, tal como refere Garcia (2006, p.113), o envelhecimento ser "caracterizado por uma fraqueza generalizada, mobilidade e equilíbrio debilitadas, denominado por fragilidade física", daí a afetação da motricidade fina. Verificada esta dificuldade, realizou-se uma atividade lúdica, jogo de cartas no computador, já que os jogos devem ser as primeiras atividades a realizar pelos seniores durante a aprendizagem da utilização do computador (King, 1997, cit. por Kachar, 2000). No entanto os seniores não apreciaram a atividade arguindo que preferem estar presencialmente a jogar com os amigos.

Destaca-se ainda um aspeto pertinente, o facto de um dos seniores do CPSB tentar utilizar, por diversas vezes, o ecrã normal como táctil. Dois seniores mostraram interesse em utilizar o sistema de ponteiro do computador em vez do rato externo, anunciando que em casa os filhos também o usam daí esta sua necessidade específica de aprendizagem.

Constatou-se também que a maioria dos seniores utilizam a tecla "enter" do 
teclado para recuar ou apagar texto, justificando-se o ato devido ao facto de possuir uma seta desenhada nesse sentido e ambígua quando comparada com a da tecla, habitualmente, imediatamente acima de "backspace".

Já no contexto de uso dos serviços de comunicação, síncrona e assíncrona, os seniores mostraram dificuldades, em todas as sessões, em encontrar o ícone "terminar sessão", indicando desagrado pelo tamanho pequeno das letras e o local onde se encontram. Para além disso, demonstraram dificuldade em memorizar os endereços das páginas, assim como distinguir entre o endereço pessoal e de correio. Um erro recorrente dos seniores é o de dar espaçamento na escrita do endereço, uns por mera distração, outros por falta de lembrança.

$\mathrm{Na}$ utilização do correio eletrónico, os seniores mostraram-se bastante motivados, nomeadamente alguns elementos do grupo de seniores do PNSFV pediu o endereço de e-mail a familiares para enviarem mensagens. No momento em que verificaram que os mesmos responderam quiseram sempre enviar novas mensagens.

Durante a realização da ação de apagar uma mensagem no correio eletrónico apenas um dos seniores não trocou "eliminar" com "eliminado", indicativo da inadequada utilização de palavras semelhantes.

$\mathrm{Na}$ utilização do Windows Live Messenger os seniores revelaram dificuldade em estabelecer contacto, por vários motivos apontados pelos mesmos: i) preferem um só clique em cima do nome do contacto pretendido; ii) após a escrita da mensagem não encontram o ícone enviar já que este não existe $\mathrm{e}$ iii) têm dificuldade em estabelecer mais do que um contacto em simultâneo. Além disso, não estavam recetivos à partilha de fotografias ou informações pessoais.

A diferença entre os elementos das diferentes instituições está na rapidez de utilização dos equipamentos e sentido de autonomia, revelando-se, os seniores do PNSFV mais aptos à utilização independente das TIC.

De referir também que a motivação revelada pelos seniores durante a utilização das ferramentas de comunicação foi distinta. Para estabelecer contacto com familiares os seniores preferem a utilização do correio eletrónico enquanto que para comunicar com os amigos nomeiam as mensagens instantâneas como mais eficazes. Esta distinção na preferência deve-se sobretudo ao conteúdo da comunicação e disponibilidade para comunicar. Com os familiares partilham poemas e mensagens mais elaboradas, lidas de acordo com a disponibilidade. Com os colegas apenas mensagens rápidas, relacionadas com encontros, atividades. Estes dados são corroborados pelos dados obtidos por Xie (2008). Os resultados sugerem que cada um dos modos particulares de CMC, devido às suas características intrínsecas de cada um, estes são utilizados para diferentes fins: a sala de conservação de voz é mais requisitada como forma de obter companhia, o fórum é usado principalmente para oferecer suporte informacional, enquanto que as mensagens instantâneas são solicitadas para apoio emocional.

\subsection{Desenvolvimento do protótipo de baixa fidelidade}

Tendo presente que a utilização das TIC pelos seniores está fortemente dependente do sucesso obtido durante a interação, elementos da equipa de investigação juntamente com os seniores participantes neste estudo desenvolveram um protótipo de baixa fidelidade, não 
executável, que retrata o ambiente virtual considerado o "ideal" ou "usável" por este grupo etário.

Não podemos esquecer que, tal como apresentado na introdução e no ponto 2.1., cada indivíduo deste grupo etário é dotado de diferentes capacidades e que o processo de envelhecimento afeta a interação com o computador. Assim, é importante envolver os seniores no desenvolvimento do protótipo, numa abordagem centrada no utilizador.

A sua participação dos seniores é ativa na transferência de poder decisório sobre características da interface, e, num futuro projeto, deverão fazer parte integrante da respetiva estratégia de validação do protótipo funcional.

O desenvolvimento do protótipo é realizado numa abordagem qualitativa, em grupos de discussão, onde os elementos da equipa de investigação têm a responsabilidade de moderar a discussão e debate de ideias e introdução de tópicos durante a discussão.

Os dados obtidos serão reproduzidos diretamente no computador, com auxílio de uma ferramenta de desenho, acrescidos das anotações em papel do moderador. $\mathrm{O}$ moderador deste momento teve o cuidado de manter uma linguagem acessível não suscetível de causar problemas de compreensão por parte dos seniores e esforçou-se para conferir um ambiente de apresentação, partilha e confronto de ideias o mais natural e cómodo, esquematizado da seguinte forma:

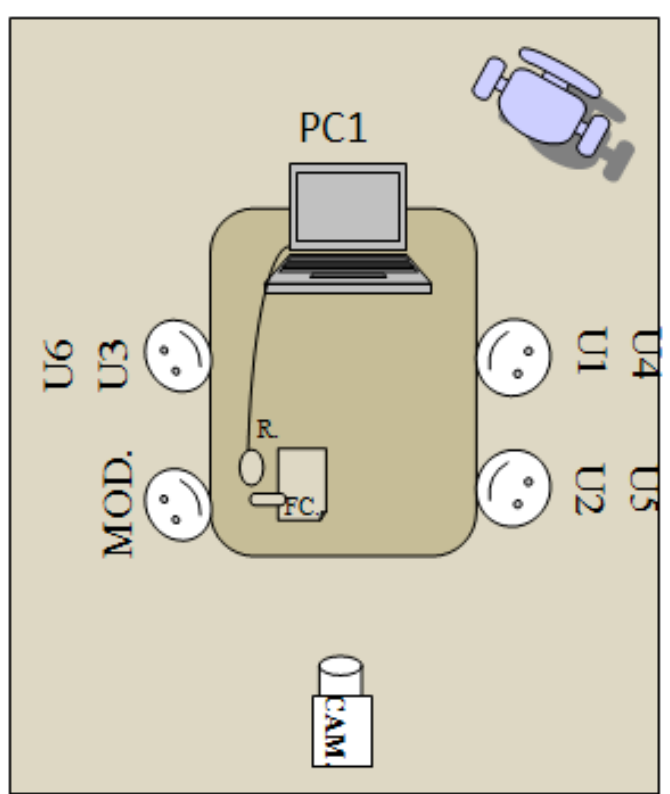

Figura 1 - Tipologia da sala: MOD. - Moderador; U1,6 - utilizadores; PC - Computador; CAM. Câmara de vídeo; R. - Rato; FC. - Folha e caneta

A tipologia da sala utilizada foi igual em ambas as instituições, de acordo com a Figura 1. Apenas se alteraram os intervenientes.

O desenvolvimento, avaliação e relação com o protótipo exigiu ao moderador (elemento da equipa de investigação) uma preparação rigorosa e orientada em função dos objetivos previamente definidos, obrigando à preparação de um guião estruturado com perguntas de resposta aberta, de acordo com as dificuldades reveladas pelos seniores durante as sessões de utilização das TIC, e com todos os elementos e funções incluídos nas ferramentas.

A primeira ferramenta a ser considerada é o correio eletrónico, especificamente o Windows Live Hotmail.

Durante o desenvolvimento do protótipo a principal exigência do estudo era conseguir uma interface sem ruído visual e de fácil utilização. 
A primeira alteração proposta contextualiza-se no endereço do serviço de correio eletrónico. $\mathrm{O}$ facto de não estar em português dificulta-lhes a memorização e a dicção. Como solução os seniores do PNSFV renomearam-no de "Correio", pelo que $\mathrm{O}$ endereço seria: www.correio.pt, enquanto os intervenientes do CPSB, preferiram "Correio eletrónico", de endereço www.correioelectronico.pt.

Considerando agora a etapa de iniciação ao Windows Live Hotmail a Figura 2 refere-se à interface original, divida por componentes ponderados, enquanto que as Figuras 3 e 4 são as propostas desenvolvidas.

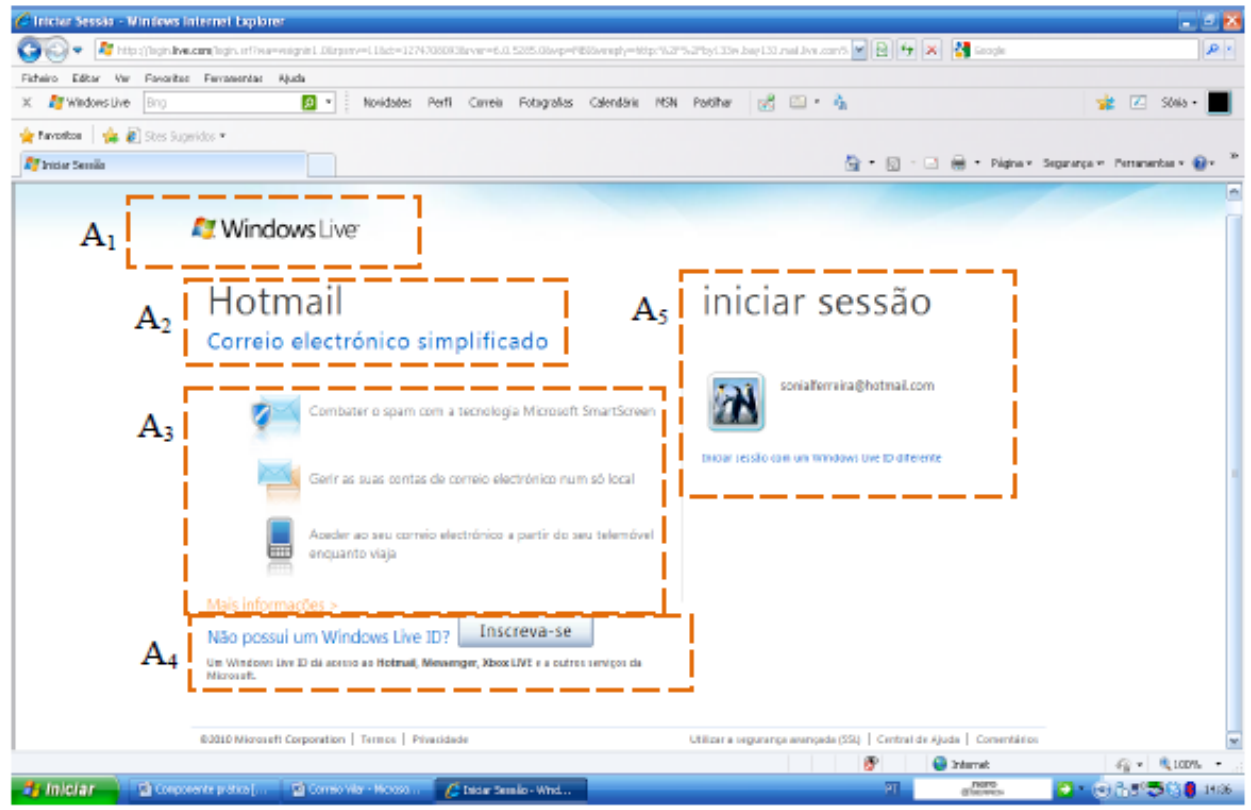

Figura 2 - Esquema original do Windws Live Hotmail, “iniciar sessão”: A1,5 - áreas

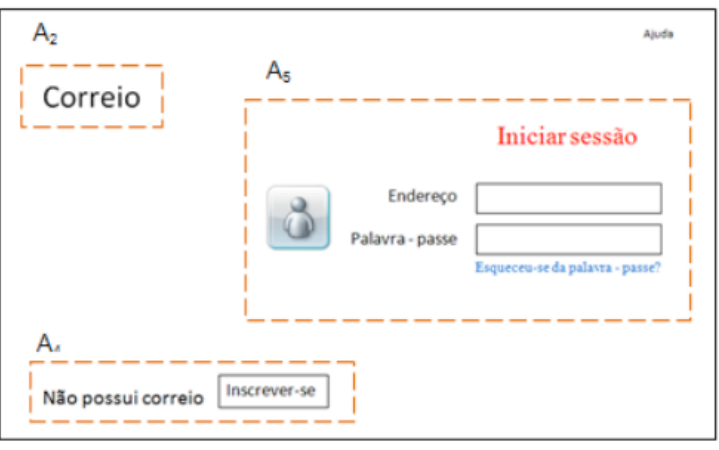

Figura 3 - Resultado relativo à etapa "iniciar sessão", PNSFV

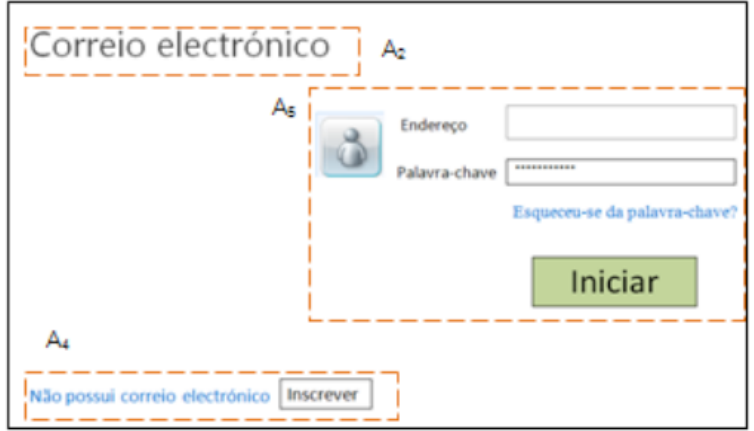

Figura 4 - Resultado relativo à etapa "iniciar sessão", CPSB 
Relativamente às áreas 1 e 3 da Figura 2 , os seniores das duas instituições consideraram desnecessária a presença desses elementos pelo que foram eliminados.

Quanto ao nome da ferramenta, em ambos os casos revelaram que seria conveniente que surgisse o nome $\mathrm{da}$ ferramenta. No CPSB consideraram que deveria surgir de forma completa "Correio eletrónico" e no PNSFV apenas a menção a "Correio". Esta deveria surgir no topo direito da página, no tamanho 36 e na cor preta.

A área de inscrição de novos utilizadores, área 4 da Figura 2, também sofreu algumas alterações, nomeadamente em relação à sua descrição.

No CPSB, os seniores consideram que deveria surgir a apresentação da funcionalidade retratada no texto

"Não possui correio eletrónico", destacado na cor azul, tamanho 20 e acompanhado do botão "Inscrever-se".

No PNSFV, os seniores simplificaram mais, preferindo o aparecimento do texto "Não possui correio", na cor preta, tamanho 24 e acompanhado do botão "Inscrever".

Em ambas as instituições os intervenientes justificaram a escolha com o facto de não compreenderem os termos que surgem um inglês, nem a necessidade e relevância de aceder a outros serviços a partir desse ponto.

No que se refere à ação de iniciar sessão propriamente dita, área 5 da Figura 2, que encerra a escrita do endereço e da palavra-passe os seniores consideraram relevante a referência escrita do local onde os mesmos deveriam ser escritos. Além disso, sugeriram que em vez de aparecer a listagem de pessoas que utilizam este serviço, deveria aparecer, aquando da escrita das primeiras letras, o endereço completo.

Relativamente ao esquema de apresentação desta secção, os seniores divergiram em alguns aspetos.

Os intervenientes do CPSB, relativamente à ajuda em caso de esquecimento da palavra-passe, quiseram alterar o texto para "esqueceu-se da palavrachave?", enquanto que no PNSFV mantiveram a original. Para ambos a duplicação da ação "iniciar sessão" foi considerada inadequada mas no CPSB os seniores mantiveram o botão na zona inferior destacado numa caixa de texto a verde "iniciar" e no PNSFV consideraram mais conveniente o seu aparecimento na zona superior com o texto a vermelho "iniciar sessão".

É importante referir que os seniores do PNSFV sugeriam a introdução de uma botão de "ajuda", a aparecer no topo esquerdo da página, que englobasse a maioria das possíveis dificuldades ou o contacto com alguém especializado.

Contudo, houve também considerações convergentes entre os seniores das duas instituições. Relativamente à imagem de apresentação, a opinião foi concordante, mantendo-a. Além disso, face à possibilidade de memorização da palavra-passe ninguém a considerou apropriada, justificando com o facto de os computadores não serem pessoais e utilizados por outras pessoas, salvaguardando a sua privacidade.

$\mathrm{Na}$ interface referente à caixa de correio, apresentada na forma original na Figura 5, foram vários os elementos gráficos considerados desnecessários pelos seniores. 


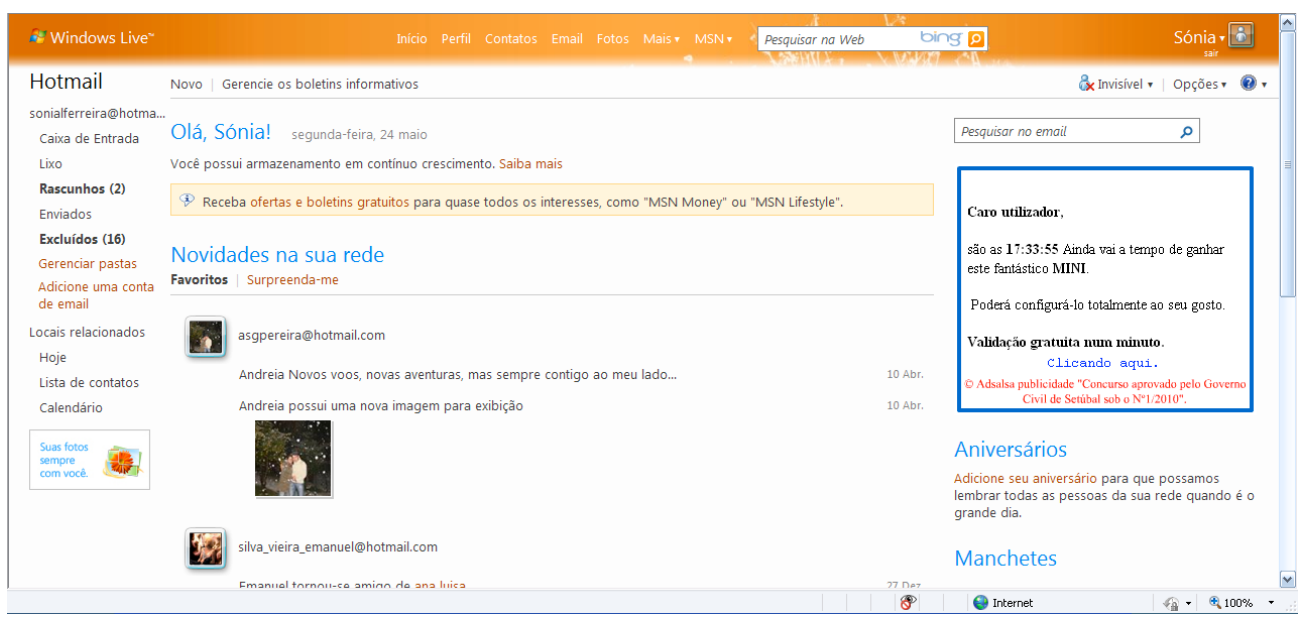

Figura 5 - Esquema original da caixa de correio eletrónico

Relativamente aos elementos que compõem o topo superior do Windows Hotmail (Início | Perfil | Contacto |Email | Fotos | Mais | Msn | Pesquisar na Web | Nome | imagem de apresentação), em ambas as instituições, os seniores quiseram eliminá-los na sua maioria, conservando apenas as opções relativas à imagem de apresentação e ao nome.

Dos elementos que compõem o topo inferior (Novo | Excluir | Lixo eletrónico | Marcar como | Mover para |imprimir), os seniores do PNSFV e do CPSB quiseram manter a opção "Novo" e "Excluir" alterando-aspara "Nova", referindo-se que serviria para escrever uma nova mensagem, e "Eliminar", respetivamente.

Quanto aos componentes de "Messenger", "Opções” e ao ícone de ajuda, os seniores apenas consideraram relevante manter a opção de ajuda mas textualmente, no topo da página. A ação de "opções" surge agora mascarada no ícone de imagem.

A opção mais válida para os seniores seria carregar no ícone relativo à imagem de apresentação é surgir uma lista de tarefas: alterar imagem | alterar nome | alterar cenário, tal como originalmente (Figura 6).

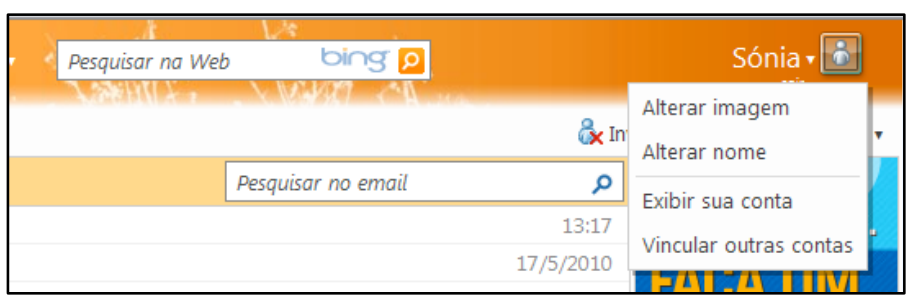

Figura 6 - Lateral esquerda do topo inferior, original

No que se refere à personalização da interface ao nível do cenário e da imagem de apresentação do correio eletrónico, os seniores de ambas as instituições consideraram-na relevante, uma vez que esse aspeto retrata de alguma forma a personalidade de cada um. 
Depois de algum tempo de análise e discussão, os seniores consideraram que a forma ideal de otimização do correio eletrónico seria manter apenas os elementos

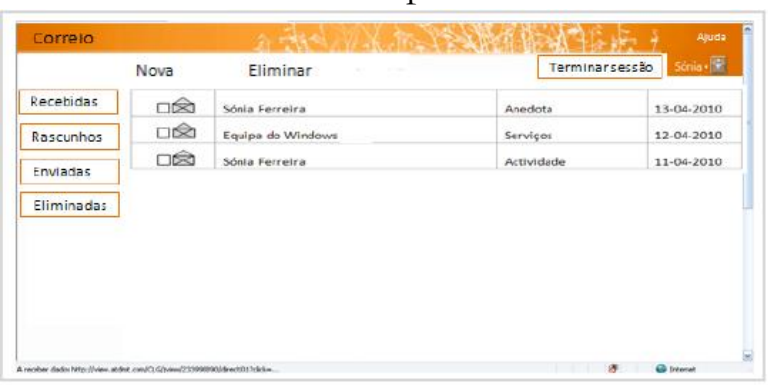

Figura 7 - Resultado conseguido para a caixa de correio, PNSFV

Os intervenientes de Vilar entenderem que é necessário manter a pasta "rascunhos" e manter a localização do elemento "terminar sessão". Os seniores do CPSB, preferiram manter o destaque em caixa, dos botões "Nova" e "Eliminar".

Quanto efetuarem a ação de escrever uma nova mensagem a disposição dos ícones deverá manter-se.

No que diz respeito ao Windows Live Messenger, o problema encontrado no Windows Hotmail relativo à designação estar um inglês dificultando a memorização e a pronúncia, mantém-se aqui também. Os seniores do CPSB e do PNSFV, depois de debaterem as possíveis designações

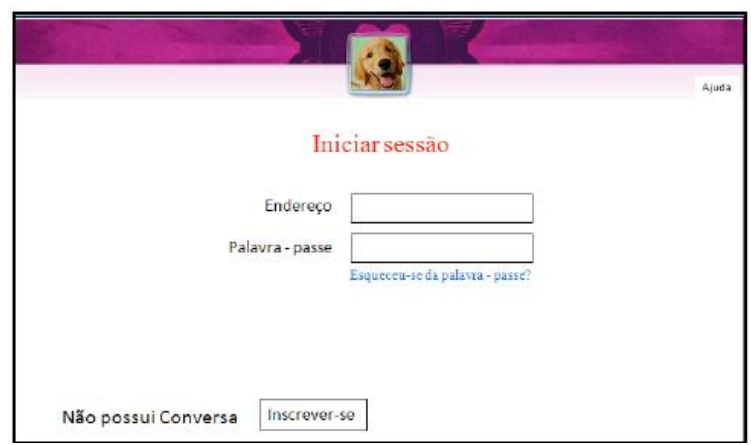

Figura 9 - Esquema relativo a "Iniciar sessão" do Windows Messenger, PNSFV

Augusto Guzzo Revista Acadêmica, 2013, № 11, 26-43 apresentados nas figuras 7 e 8 , e na disposição em que surgem.

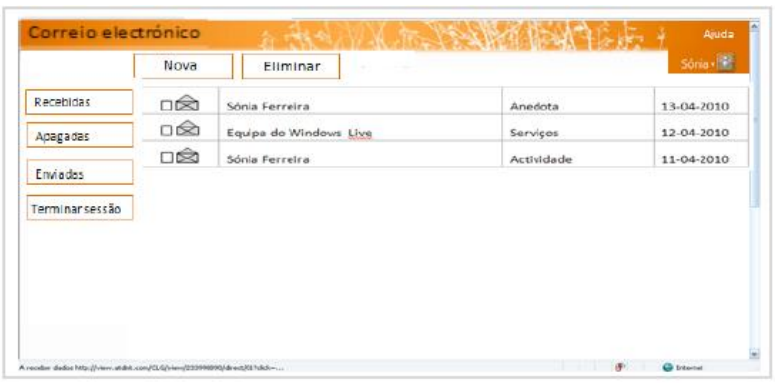

Figura 8 - Resultado conseguido para a caixa de correio, CPSB

chegaram a uma conclusão muito próxima, conversador e conversa, respetivamente.

As figuras 9 e 10 mostraram-nos o esquema adequado da interface, conseguidas pelos seniores. Os grupos foram convergentes quanto aos elementos a manter apenas divergiram na sua disposição. Os intervenientes foram imperativos sobretudo face ao elemento "memorizar palavrapasse", considerando totalmente inadequado, assim como em relação à duplicação do termo "inicia sessão" na interface original, fator de confusão. Unânime foi também a ideia de legendar os locais destinados à escrita do endereço e da palavrapasse e do botão ajuda.

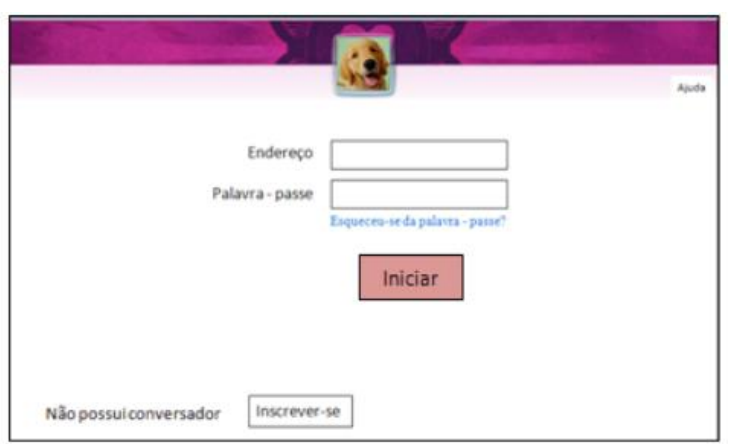

Figura 10 - Esquema relativo a "Iniciar sessão" do Windows Messenger, CPSB 
Depois de iniciar a sessão, de forma geral os seniores conseguiram chegar a um entendimento relativamente à interface, semelhante nos dois grupos. A única discordância prende-se com o facto de os seniores de Vilar considerarem que os elementos "alterar cenário", "alterar imagem" e "terminar sessão" devem aparecer mascarados com um clique na fotografia do utilizador, enquanto que os seniores do CPSB preferem que a ação de terminar sessão surja destacada na página.

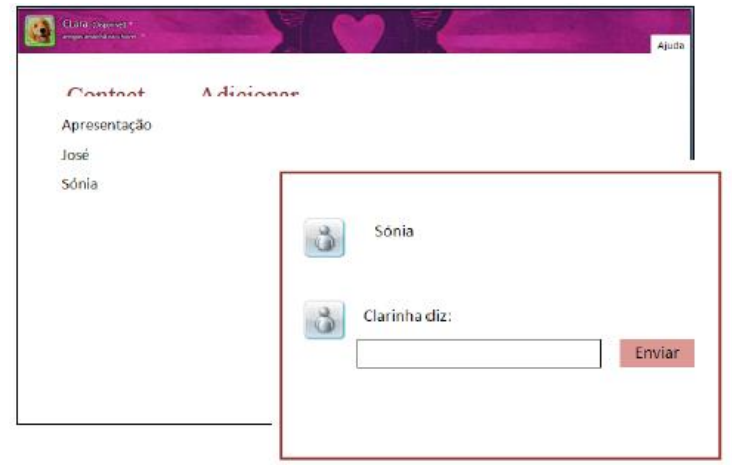

Figura 11 - Protótipo relativo ao Windows Messenger, PNSFV

Citando Vechiato e Vediotti (2008), a ergonomia da informação disponível nestes serviços deve permitir a inclusão digital dos seniores. A comparação entre as interfaces iniciais e as propostas por este grupo etário revelam todas as alterações necessárias à criação de ambientes adequados à utilização pelos seniores.

\section{Considerações finais}

Os seniores tiveram oportunidade de contactar com serviços de comunicação diferentes, síncrona e assíncrona, respetivamente as ferramentas de mensagens instantâneas e de correio eletrónico. Por observação, verificou-se que os seniores, quando experimentaram o Windows Live Messenger depois utilizarem o Windows Live Hotmail, mostraram motivações diferentes.
A tarefa de estabelecer contacto é feita com apenas um clique em cima do nome do contacto e a adição de novos contactos deve ser conseguida em apenas uma etapa.

A caixa de troca de mensagens deve apresentar-se, na opinião dos dois grupos, tal como vemos nas Figuras 11 e 12. Visualmente sem ruído e com um botão para enviar a mensagem, mantendo-se o nome e a imagem dos contactos.

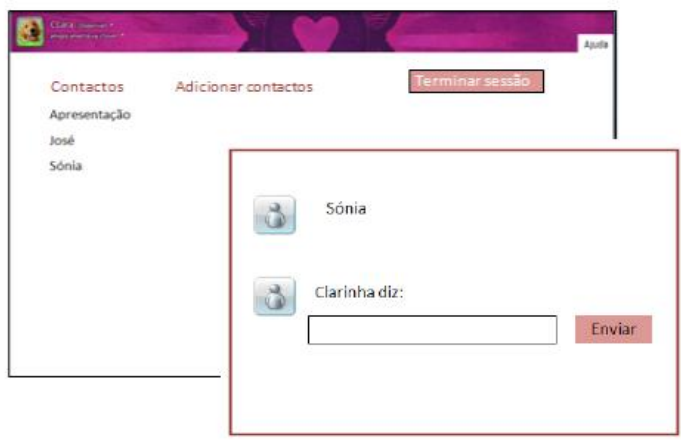

Figura 12 - Protótipo relativo ao Windows Messenger, CPSB

Os resultados obtidos por Verona et.al (2006) assemelham-se aos que obtivemos. Os autores revelam que o correio eletrónico é uma boa opção de comunicação para os seniores, já que permite comunicar com familiares distantes, com mais frequência.

Os seniores que fizeram parte deste estudo referiram que para estabelecer contacto com familiares preferem o correio eletrónico, e para comunicar com os amigos dão preferência às mensagens rápidas.

Os dados obtidos durante a observação participante e o desenvolvimento do protótipo de baixa fidelidade permite-nos considerar que é crucial a adaptação das interfaces dos serviços de comunicação às necessidades e características dos utilizadores. 
No estudo desenvolvido por King (1997, cit. por Kachar, 2000) tal como neste verifica-se que são vários os fatores a ter em conta para o sucesso na interação entre os seniores e o computador. Relativamente à ergonomia física dos dispositivos devemos ter em atenção o tamanho e a iluminação do monitor, teclado e rato adaptados de forma mais funcional. A interface das ferramentas disponíveis não deve possuir ruído visual, os carateres com fontes e tamanho grandes, a disposição dos ícones deve ser conseguida com a participação ativa dos seniores e disponibilização de ajuda online. Algumas das dificuldades de aprendizagem em contexto de utilização das TIC pelos seniores podem ser superadas utilizando estratégias específicas, nomeadamente, no aumento gradual na dificuldade das tarefas, disponibilização de tempo para a aprendizagem ao ritmo individual e formação de grupos pequenos.

Ao longo do contacto estabelecido entre a equipe de investigação e o grupo idoso foi possível verificar que o avanço da idade não inviabiliza a apropriação e o domínio dos recursos tecnológicos pelos seniores, mas poderá limitá-los apenas no tempo ou quanto à eficiência de execução das tarefas.

Diante do exposto, pode-se acrescentar que o cidadão idoso faz parte de um público merecedor de estritos e mais estudos, nomeadamente, em investigações qualitativas.

\section{Referências Bibliográficas}

1. BARbOSA, Â. A., CHEIRAN, J. F. P., VIEIRA, M. C. Inclusão digital na terceira idade: avaliação de usabilidade em sites de cadastro de correio eletrónico. Universidade Federal do Rio Grande do Sul. 2008.
2. BATTLE, L., HOFFMAN, B. Design Patterns and Guidelines for Usable and Accessible Web Applications. Usability Professionals' Association Proceedings. 2004. CASANOVA, J. (dir.). Escolaridade na União Europeia: Portugal do insucesso. Avante, 1435 - 31, 2001. 18

3. CHISNELL, D., LEE, A. \& REDISH, J. Designing Web Sites for Older Users: Comparing AARP's Studies to Earlier Findings. 2004. Disponível em: <www.aarp.org/olderwiserwired/owwfeatur es/Articles/a2004-03-03-

comparisonstudies.html>. Acesso em 26 mai. 2011.

4. COMISSÃO EUROPEIA. O futuro demográfico da Europa: transformar um desafio em oportunidade. 2006. Disponível em:

$<$ http:/ / eurlex.europa.eu/LexUriServ/LexU riServ.do?uri=COM:2006:0571:FIN:PT:HT ML>. Acesso em 15 dez 2009.

5. FISK, A., et al.. Designing for older adults: Principles and Creative Human Factors Approaches.

6. Book, CRC Press LLC, 2004.

7. FREITAS, M., et al. Perspectivas das pesquisas em gerontologia e geriatria: revisão de literature. Revista Latino Americana de Enfermagem, vol.10, 2, p. 221-228, 2002.

8. GREGOR, P., NEWELL, F. e ZAJICEK, M.. Solutions for aging: Designing for dynamic diversity: interfaces for older people. Conference paper, Proceedings of the fifth international ACM conference on Assistive technologies. ACM digital library. 2004.

9. HAWTHORN, D.. How universal is good design for older users?. Conference paper, ACM SIGCAPH Computers and the Physically Handicapped, Proceedings of the 2003 conference on universal usability, 7374, 2003. 
10. ISO 9241-11. Ergonomic requirements for office work with visual display terminals (VDTs) - Part 11: Guidance on usability. 1998.

11. KACHAR, V. A terceira idade e o computador: interação e transformações significativas. Terceira Idade e Informática: aprender revelando potencialidades, São Paulo, 11:19, 2000.

12. LINDGAARD, G. Usability Testing and System Evaluation. London, UK: Chapman \& Hall, 1994.

13. MORAN, T. The Command Language Grammars: a representation for the user interface of interactive computer systems. In: International Journal of Man-Machine Studies 15:3-50, Academic Press, 1981.

14. MORRELL, R. W., et al. National Institute on Aging. Older adults and information technology: A compendium of scientific research and web site accessibility guidelines. Report, National Institutes of Health, 2003.

15. NIA (National Institute on Aging). Making your web site senior friendly. National Institute on Aging and the National Library of Medicine, 2002. 19

16. NIELSEN, J.. Usability for Sénior Citizens. 2002. Disponível em $<$ http://www.useit.com/alertbox/seniors.ht $\mathrm{ml}>$. Acesso em 10 Jun. 2010.

17. NIELSEN, J.. Usability 101: Introduction to Usability. 2003. Disponível em:

<http://www.useit.com/alertbox/20030825 .html>. Acesso em 10 Jun. 2010.

18. PREECE, J., et al. Human-Computer interaction. Reading, MA. Addison-Wesley, 1994.

19. PREECE, J., ROGERS, Y. e SHARP H. Interaction design - beyond human computer interaction. John Wiley \& Sons, Inc, USA, 2002.

20. RAABE, A.; et al.. Promovendo inclusão digital dos idosos através de práticas de design participatório. Contrapontos, 5, p. 417-430, 2005.

21. SALES, M.; CYBIS, W. Desenvolvimento de um checklist para a avaliação de acessibilidade da Web para usuários idosos. Dissertação de mestrado em Engenharia de Produção, Universidade Federal de Santa Catarina, Florianópolis, 2002.

22. SOUSA, P. Avaliação da usabilidade e organização e representação da informação do novo website do

23. SDI da FEUP. 2009. Disponível em <http://badinfo.apbad.pt/Congresso9/CO M48.pdf>. Acesso em 05 jun. 2010.

24. SPAGNOLLI, A. (Org.). Development of High Therapeutic Value IST-based Games for Monitoring and Improving the Quality of the Life of Elderly People. In European Commission IST Programme: Elder Games. University of Padova, 2006.

25. VECHIATO, F.; VIDOT'TI, S. (2008). Avaliação da usabilidade de ambientes informacionais digitais sobre envelhecimento humano no contexto da arquitetura da informação: aplicação de avaliação heurística e testes de usabilidade com usuários idosos. Disponível em $<$ http://libdigi.unicamp.br/document/?cod $\mathrm{e}=23484>$. Acesso em: 04 out. 2009.

26. VERONA, S. M., et al. Perceção do idoso em relação à Internet. Temas em Psicologia. v. 14, n. ${ }^{\circ}$ 2, p.189- 197, 2006.

27. ZAPHIRIS P., et al. Age-centered Research-Based Web Design Guidelines. Proceedings of CHI 2005 Conference on 
Human Factors in Computing Systems.

Portland, USA, 1 April- 7 April 2005, 2005.

28. XIE, B. Multimodal Computer-Mediated Communication and Social Support among Older Chinese Internet Users. Journal of Computer-Mediated Communication. Vol. 13, p. 728-750, 2008 